\title{
Corrosion Evaluation of Epoxy-Coated Bars by Electrochemical Impedance Spectroscopy
}

\author{
Oan-Chul Choi, ${ }^{1 * *}$ Young-Su Park, ${ }^{2)}$ and Hyung-Yun Ryu ${ }^{3)}$
}

(Received January 28, 2008, Revised September 30, 2008, Accepted October 31, 2008)

\begin{abstract}
Southern exposure test specimens were used to evaluate corrosion performance of epoxy-coated reinforcing bars in chloride contaminated concrete by electrochemical impedance spectroscopy method. The test specimens with conventional bars, epoxy-coated bars and corrosion inhibitors were subjected 48 weekly cycles of ponding with sodium chloride solution and drying. The polarization resistance obtained from the Nyquist plot was the key parameter to characterize the degree of reinforcement corrosion. The impedance spectra of specimens with epoxy-coated bars are mainly governed by the arc of the interfacial film and the resistance against the charge transfer through the coating is an order of magnitude higher than that of the reference steel bars. Test results show good performance of epoxy-coated bars, although the coatings had holes simulating partial damage, and the effectiveness of corrosion-inhibiting additives. The corrosion rate obtained from the impedance spectroscopy method is equivalent to those determined by the linear polarization method for estimating the rate of corrosion of reinforcing steel in concrete structures.
\end{abstract}

Keywords: epoxy-coated bars, corrosion inhibitor, corrosion rate, electrochemical impedance spectroscopy

\section{Introduction}

The deterioration of concrete structures has received significant attention in recent years. A major contributing factor to this deterioration is reinforcing steel corrosion. Much research has been performed to investigate possible solutions to the problem. Some of the remedial measures that have been studied include the use of corrosion-inhibiting admixtures, epoxy-coated reinforcing steel, waterproofing membranes, sealers, galvanized reinforcing steel, electrochemical removal of chlorides, and cathodic protection.

The principal function of these corrosion-protection systems is to prevent aggressive agents, mainly chloride ions, from attacking the surface of the reinforcing bars. Desalination removes chloride ions from the surface of reinforcing steel by electrical mitigation. ${ }^{1,2}$ The use of epoxy-coated bars has been considered as one of the most cost-effective solutions to the wide spread corrosion problem due to their convenient and economical application to concrete structures. ${ }^{3,4}$ Epoxy-coating provides a physical barriers to the ingress of aggressive agents, and cathodic protection electrochemically stabilizes the steel /concrete interface.

The actual corrosion process is electrochemical. There are several methods of measuring the true, instantaneous rate of corrosion

\footnotetext{
${ }^{1)}$ KCI Member, School of Architecture, Soongsil University, Seoul 156-743, Korea. E-mail: occhoi@ssu.ac.kr

${ }^{2)}$ KCI Member, Hundai Construction Co., Ltd, Seoul, 110-920, Korea.

${ }^{3)}$ KCI Member, School of Architecture, Soongsil University, Seoul, 156-743, Korea.

Copyright (c) 2008, Korea Concrete Institute. All rights reserved, including the making of copies without the written permission of the copyright proprietors.
}

and many of these are electrochemical methods. They rely on measuring changes in the half cell potential as it is perturbed, and use electrochemical theory to calculate the corrosion current and hence the rate of corrosion. Linear polarization technique has proven itself to be useful in measuring corrosion rates of reinforcement in concrete. The corrosion density can be determined by the concept of reaction rates and polarization of electrochemical reactions at the metal surface.

Electrochemical impedance spectroscopy (EIS) is one of the widely used analysis techniques in the field of electrochemistry, electrode kinetics, solid state devices and corrosion. ${ }^{1,2,5}$ The advantages of the EIS method are principally the precision with which a small sine-wave perturbation can be measured in an electrically noisy environment.

The use of this impedance spectroscopy technique in reinforced concrete corrosion study was initiated only in the 1980s. ${ }^{6}$ EIS methods have been applied to corroding system in as an effort to determine the mechanisms of the corroding process, or to measure the corrosion resistance. ${ }^{7,8} \mathrm{Gu}$ et al. studied corrosion inhibitor performance in chloride contaminated concrete by electrochemical impedance spectroscopy method. An equivalent circuit model considering the physical characteristics of the rebar/concrete interface was used to simulate the impedance spectra. Andrade et al. studied the importance of geometrical considerations in the measurement of steel corrosion in concrete by means of AC impedance. ${ }^{7}$ However, interpretation of an impedance spectrum is difficult due to the complexity of cement paste and concrete micro-structural changes taking place on steel surfaces. The analysis is strongly dependent on how the electrical components are selected and the extent to which they represent the microstructure of the steel/concrete interface. 
This experimental study explores the role of the epoxy-coated rebar/concrete interface on corrosion by the electrochemical impedance spectroscopy technique. This paper describes the test results to evaluate corrosion performance of epoxy-coated bars used in chloride contaminated reinforced concrete structures.

\section{Experimental program}

\subsection{Materials and concrete mix}

Coarse aggregate (crushed granite with nominal size of $19 \mathrm{~mm}$ ) and fine aggregate (a fineness of modulus of 2.8) were used in this experiment. Aggregate gradation, which complied with ASTM C33 was used, as well as ordinary. Portland cement (Type 1), which complied with ASTM C114. The mix properties of concrete are given in Table 1.

The materials tested also include epoxy-coated bars, conventional reinforcing steel and concrete containing corrosion inhibitors. D16 bars were used and each bar was $305 \mathrm{~mm}$ long. Epoxycoated bars with holes simulating cracks or minor damage during construction were used. The epoxy coating was intentionally damaged by drilling four holes of $3.2 \mathrm{~mm}$ diameter through the coating on each epoxy-coated bar, as studied by Balma et al.

The current study evaluated three corrosion inhibitors, DCI-S (calcium nitrite), Rheocrete 222+ (amines and ester) and Hycrete. Darex Corrosion Inhibitor is considered to be and anodic inhibitor since it works to minimize the anodic reaction by reacting with ferrous ions to form a $\gamma$-ferric oxide, layer at the anode. DCI-S is composed of approximately $30 \%$ calcium nitrite and $70 \%$ water (specific gravity $=1.2 \sim 1.3$, solids content $=33 \%$ ). Rheocrete $222+$ is a combination of amines and esters in water (specific gravity $=$ $0.98 \sim 0.99$, solids content $=10 \sim 16 \%$ ). This inhibitor protects the reinforcing steel in forming a protective film on the steel surface and reducing the penetration of chloride ions into the concrete. Hycrete DSS consists of approximately $75 \%$ of water and $25 \%$ mixtures of organic alkenyl dicarboxylic acid salts and additives (specific gravity $=1.04 \sim 1.07$, solids content $=19.5 \sim 20.5 \%$ ). ${ }^{4,9,10}$

The material combinations and the number of specimens are summarized in Table 2.

\subsection{Test specimens and experimental set-up}

The southern exposure specimens in this study consist of small concrete slabs containing two mats of steel as illustrated in Fig. 1. The slabs are subjected to alternating ponding and drying cycles with a salt solution. The southern exposure test was originally developed by Pfeifer and Scali to simulate the exposure conditions in southern climates, thus named Southern Exposure. ${ }^{11}$ A flexural crack was induced in the specimens to evaluate the behavior of cracked concrete.

To determine the corrosion rate of the reinforcing bar, the test
Table 2 Bench scale test specimens.

\begin{tabular}{c|c|c|c}
\hline $\begin{array}{c}\text { Specimens } \\
\text { designation }\end{array}$ & $\begin{array}{c}\text { Steel } \\
\text { designation* }\end{array}$ & w/c & Inhibitors \\
\hline \hline CB -N & Conv. & 0.45 & None \\
\hline CB-ERC & ECR & 0.45 & None \\
\hline CB-ERC-DCI & ECR-4h & 0.45 & DCI-S \\
\hline CB-ERC-HY & ECR-4h & 0.45 & Hycrete DSS \\
\hline CB-ERC-RH & ECR-4h & 0.45 & Rheocrete 222+ \\
\hline
\end{tabular}

*Conv. = conventional steel. $\mathrm{ECR}=$ normal epoxy-coated steel $4 \mathrm{~h}=$ epoxy coated bar penetrated with 4 holes of $0.3 \mathrm{~mm}$ diameter

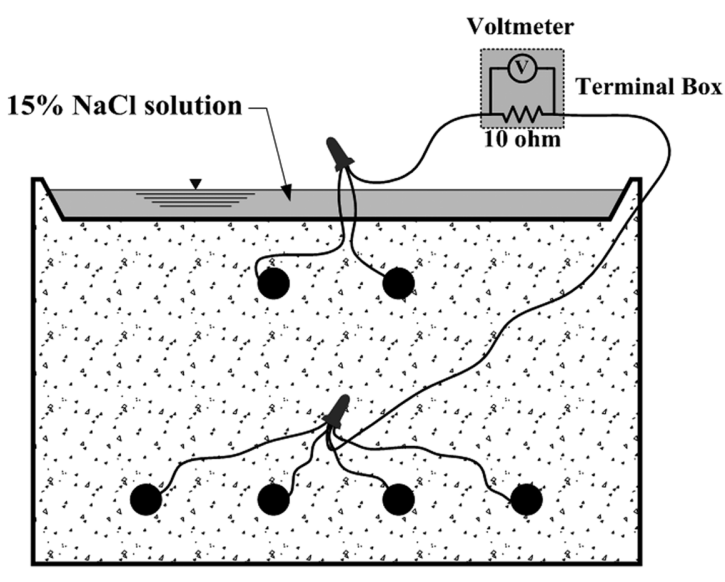

Fig. 1 Schematic diagram of a typical concrete test.

specimens were placed in a tap water bath containing 15 percent sodium chloride. The solution was aerated for at least fifteen minutes prior to testing. The cycle for these tests consisted of ponding the specimens for 100 hours with a 15 percent $\mathrm{NaCl}$ solution followed by drying in a heat chamber at $38 \mathrm{C}$ for 68 hours. This weekly cycle is repeated 48 times.

The specimen consists of six reinforcing bars embedded in a concrete slab with a length of $305 \mathrm{~mm}$, a width of $305 \mathrm{~mm}$ and a height of $178 \mathrm{~mm}$. Two reinforcing bars as the top mat were placed with a clear cover of $25 \mathrm{~mm}$ and the bottom mat consists of four bars. The bars were drilled and tapped at both ends so that bolts can be fixed in molds to provide an electrical connection to the bars during tests. The top mat and bottom mats were connected to separate biding posts. The posts were connected by 10 resistors. A dam was cast around the top surface of the specimen to facilitate ponding during the test. For the cracked slab specimens, a slot was cut at the bottom of the slab and a $0.3 \mathrm{~mm}$ and $300 \mathrm{~mm}$ long stainless steel shim was inserted to produce a simulated crack to the steel surface. Between 8 and 10 hours after casting, the stainless steel shim was removed, and a uniform crack was created in the slab.

Table 1 Concrete mix proportions.

\begin{tabular}{c|c|c|c|c|c|c|c}
\hline $\begin{array}{c}\text { Water } \\
\left(\mathrm{kg} / \mathrm{m}^{3}\right)\end{array}$ & $\begin{array}{c}\text { Cement } \\
\left(\mathrm{kg} / \mathrm{m}^{3}\right)\end{array}$ & $\begin{array}{c}\mathrm{CA} \\
\left(\mathrm{kg} / \mathrm{m}^{3}\right)\end{array}$ & $\begin{array}{c}\text { FA } \\
\left(\mathrm{kg} / \mathrm{m}^{3}\right)\end{array}$ & $\begin{array}{c}\text { AE } \\
\left(\mathrm{mL} / \mathrm{m}^{3}\right)\end{array}$ & $\begin{array}{c}\text { Rheocrete } \\
\left(\mathrm{mL} / \mathrm{m}^{3}\right)\end{array}$ & $\begin{array}{c}\text { DCI-S } \\
\left(\mathrm{mL} / \mathrm{m}^{3}\right)\end{array}$ & $\begin{array}{c}\text { Hycrete } \\
\left(\mathrm{kg} / \mathrm{m}^{3}\right)\end{array}$ \\
\hline \hline 160 & 355 & 874 & 852 & 90 & - & - & - \\
\hline 156 & 355 & 874 & 852 & 320 & 5000 & - & - \\
\hline 147 & 355 & 874 & 852 & 140 & - & 15000 & - \\
\hline 154 & 355 & 874 & 852 & 35 & - & - & 8 \\
\hline
\end{tabular}

Inhibitor dosage rate

Rheocrete $222+: 5 \mathrm{~L} / \mathrm{m}^{3}$, DCI-S: $15 \mathrm{~L} / \mathrm{m}^{3}$, Hycrete: $2.25 \%$ of cement 


\subsection{Electrochemical impedance spectroscopy test}

In the tests, the top mats of the reinforcing bar were used as the working electrode, a saturated calomel electrode immersed in salt solution on the top of the specimen was used as the reference electrode, and a platinum strip immersed in salt solution on the top of the specimen is used as the counter electrode.

The surface area, the equivalent weight, and the density of steel were $304 \mathrm{~cm}^{2}, 27.93 \mathrm{~g}$ and $7.8 \mathrm{~g} / \mathrm{cm}^{3}$, respectively. The corrosion cell setup is shown in Fig. 2. The tests were performed using a PC4/750 Potentiostat and EIS300 Electrochemical Impedance Spectroscopy system, from Gamry Instruments. ${ }^{12}$

A small sinusoidal voltage signal of $10 \mathrm{mV}$ was applied over the range of frequencies $100 \mathrm{kHz}$ to $0.05 \mathrm{~Hz}$. The current required to cause this voltage perturbation was measured as well as the phase shift of the current and voltage characteristics. These tests were done with EIS HF Frequency Response Analyzer and associated software to control the test procedures and analyze the data.

\subsection{Linear polarization test}

Results of AC impedance are compared with previous results obtained by linear polarization (LP) resistance technique. Tests of LP were conducted using a Potentiostat/Galvanostat and an associated software package to control the test procedures and analyze the data. ${ }^{13}$ A linear fit of the data to a standard model gives an estimate of the potential resistance $R_{p}$, used to calculate corrosion density $I_{\text {corr }}$ Polarization experiments were performed at a scan rate of $0.1 \mathrm{mV} / \mathrm{s}$ (ASTM G59 recommends a scan rate less than $0.1667 \mathrm{mV} / \mathrm{s}$ ). They were initiated at $20 \mathrm{mV}$ below the corrosion potential and terminated at a maximum of $20 \mathrm{mV}$ above the corrosion potential. The duration of each test was between 6 and 7 minutes.

Tests were performed on each specimen with at least 15 minutes between consecutives on the same sample to allow the reinforcement to depolarize. The software provided by Gamry uses a linear fit of data in the selected range to find polarization resistance. Details of the polarization test for the same group of the specimens were described on the paper by the author. ${ }^{14}$

\section{Results and discussions}

\subsection{Impedance behavior and simulation of the steel-concrete interface}

The impedance spectra obtained from the specimens with conventional steel and epoxy-coated bars are shown in Fig. 3 and Fig. 4. Data are presented in the Nyquist plots of Real impedance ver-

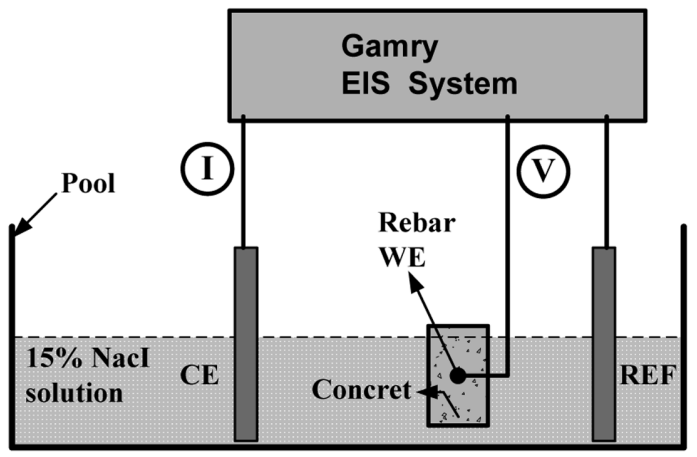

Fig. 2 Corrosion control cell by anodic EIS.

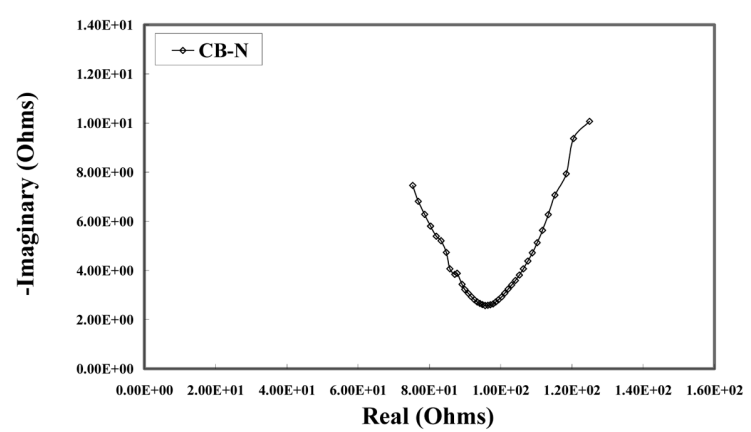

(a) Conventional bar

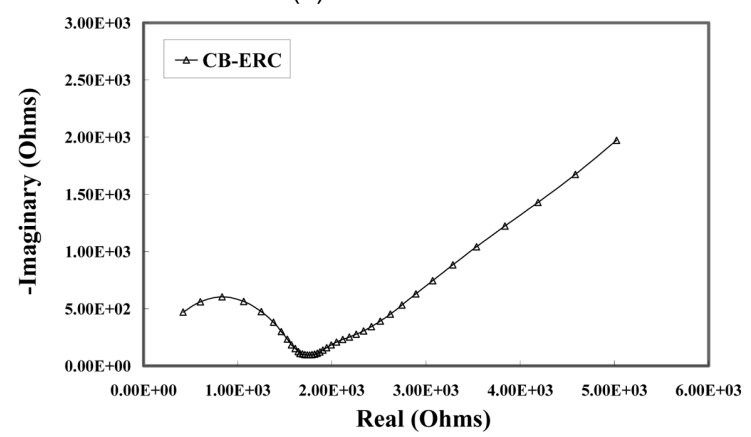

(b) Epoxy-coated bar

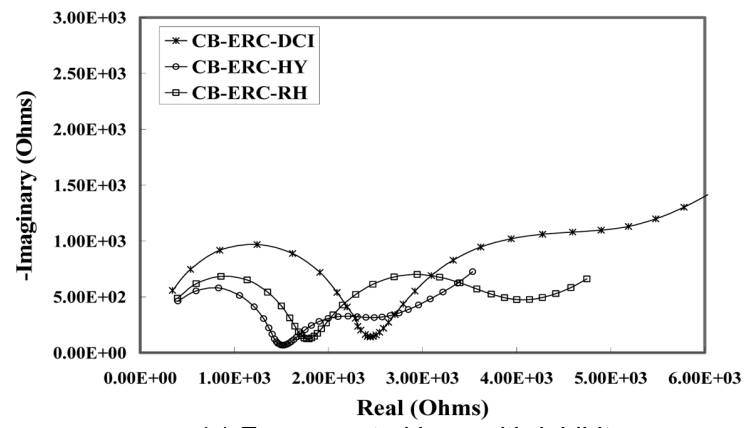

(c) Epoxy-coated bars with inhibitors

Fig. 3 Impedance spectra of Real vs. Imaginary plot.

sus Imaginary impedance shown in Fig. 3. Bode plots, Phase angle versus $\log$ (frequency) and $\log$ (modulus) versus $\log$ (frequency) are shown in Fig. 4. Different symbols of the curves correspond to the test specimens with different inhibitors.

Examination of all the impedance spectra shows some common characteristics given as follows. One partial arc and an entire arc were observed in two frequency regions in the Real vs. Imaginary plots for all the specimens as shown Fig. 3. A tail of an arc depicted in the high frequency range $10 \mathrm{kHz}$ and higher) was followed by a depressed arc at frequencies ranging form $10 \mathrm{kHz}$ to 1 $\mathrm{Hz}$. In the very low frequency region a large and incomplete arc corresponding to the surface corrosion process was observed.

A previous study by $\mathrm{Gu}$ et al. simulated using a modified electrical equivalent circuit and observed three frequency regions and two partial arc. As shown in Fig. 5, the circuit consists of three parallel combinations of a pure resistor and a frequency dependant capacitor representing the concrete matrix, the interface film, and steel surface corrosion process arcs in the Real versus Imaginary plot.

In this study, the Nyquist plots for the specimen with epoxy coating show one partial and one large entire arc, although the specimen with conventional bar appears to show the one partial and one small entire arcs. The impedance spectra of specimens with coated bars are mainly governed by the arc of the interfacial film. 


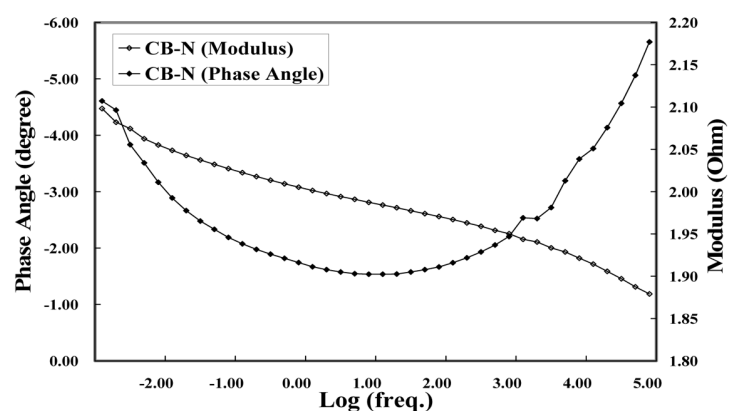

(a) Conventional bar

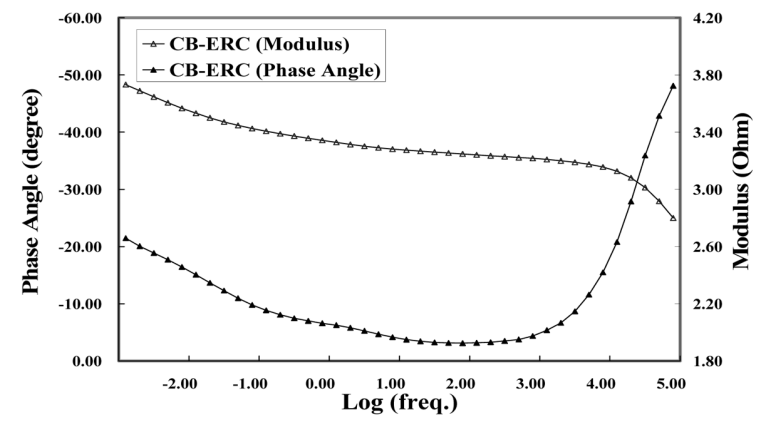

(b) Epoxy-coated bar

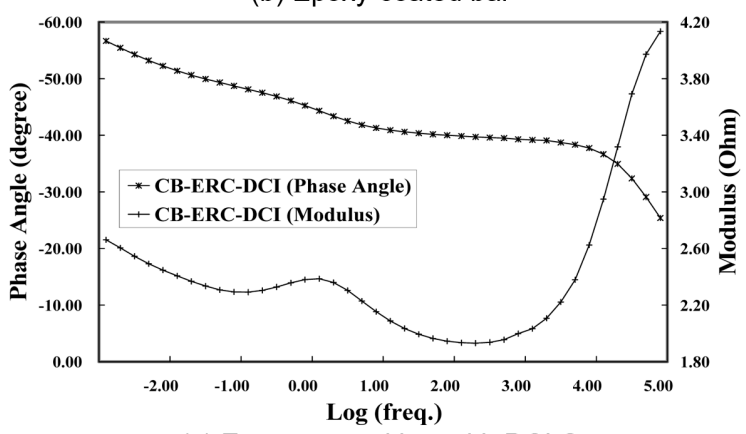

(c) Epoxy-coated bar with DCl-S

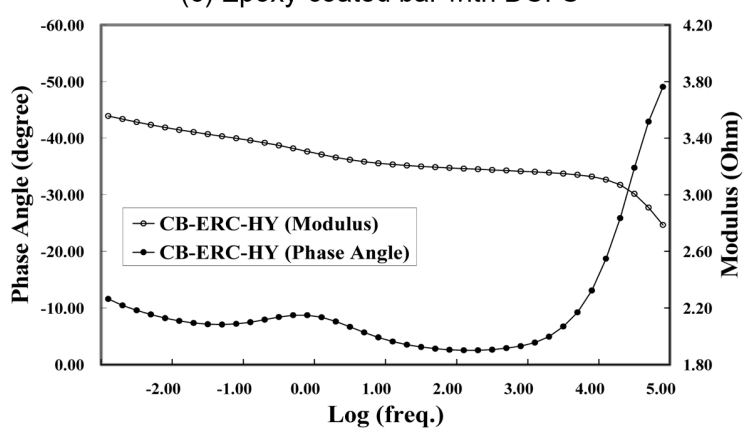

(d) Epoxy-coated bar with hycrete DDS

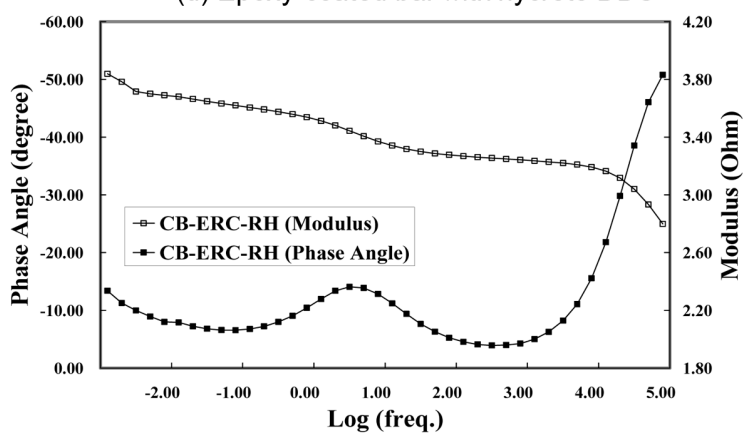

(e) Epoxy-coated bar with rheocrete 222+

Fig. 4 Impedance spectra of Phase Angle and Modulus vs. Log (frequency) plot.

The two regions corresponding to these two arcs can also be distinguished in the Bode plots where peaks or partial peaks of the

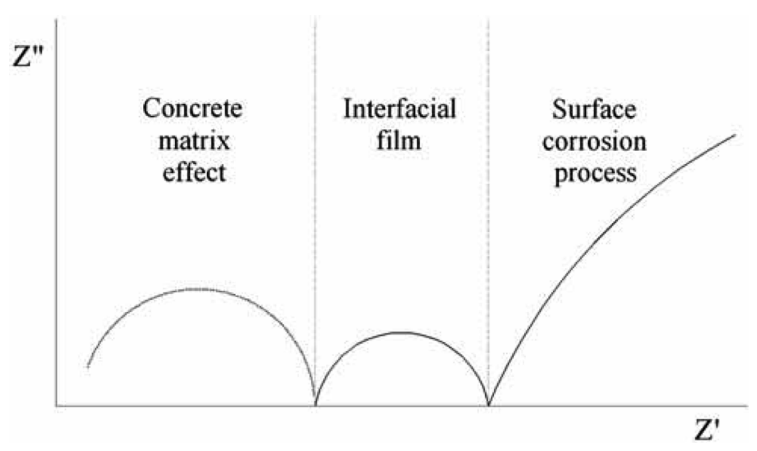

Fig. 5 Three parallel combinations representing three arcs in the Nyquist plot.

phase angle shift were observed in the phase angle versus logarithmic frequency plots as shown in Fig. 4.

Two slope changes in the logarithmic modulus, $|Z|$, versus logarithmic frequency plots were also observed. The Real versus Imaginary plot is good enough to judge the excellence of the simulation since the simulation of the high frequency portion can be seen clearly.

Presenting the simulation results in the Bode plot format can provide additional information. Specific comparisons and corrosion rates for the test specimens are described as follows.

\section{$3.2 R_{p}$ and corrosion rate}

The key parameters from impedance spectra of the specimens with conventional steel bar and epoxy-coated bars along with corrosion inhibitors are determined from the Nyquist and Bode plots and listed in Table 3.

From Nyquist plots, the values of $R_{p+} R_{\Omega}$ are determined for each specimen. At very high frequency, the imaginary component, $Z$ ", disappears, leaving only the solution resistance, $R_{\Omega}$ and at very low frequency, $Z$ " again disappears, leaving a sum of $R_{\Omega}$ and the polarization resistance, $R_{p}$. The polarization of resistance of conventional bar is much lower than those of specimens of epoxycoated bars. The values of $R_{p}$ are determined by multiplying the surface area of bars and listed in the Table 3 . The maximum values of phase angle of each specimen and the values of relative slope changes in the logarithmic modulus, $\log |Z|$, versus frequency $f$ in cycles per second from Bode plots are also presented in the Table 3.

The maximum absolute value of the phase angel of the steel kinetic arc has been used to describe the degree of surface corrosion of steel. The decrease of maximum phase angle was also observed in reinforced concrete specimens immersed in chloride solution. In Fig. 6, the plots of absolute value of phase angle versus specimen type are given. Specimens with epoxy coated bars

Table 3 Spectra of specimens from EIS test results.

\begin{tabular}{|c|c|c|c|}
\hline Specimens & $\begin{array}{c}\left(R_{p+} R_{\Omega}\right)-\left(R_{\Omega}\right) \\
\quad(\mathrm{ohm})\end{array}$ & $\begin{array}{c}R_{p^{+}} R_{\Omega} \\
\text { (ohm) }\end{array}$ & $\begin{array}{c}R_{p} \\
\left(\mathrm{ohm} \mathrm{cm} \mathrm{cm}^{2} \times 10^{6}\right)\end{array}$ \\
\hline $\mathrm{CB}-\mathrm{N}$ & 0.22 & 95.7 & 0.0291 \\
\hline CB-ERC & 0.95 & 1710 & 0.520 \\
\hline CB-ERC-DCI & 1.35 & 2480 & 0.754 \\
\hline CB-ERC-HY & 1.07 & 1500 & 0.456 \\
\hline CB-ERC-RH & 0.75 & 1770 & 0.538 \\
\hline
\end{tabular}




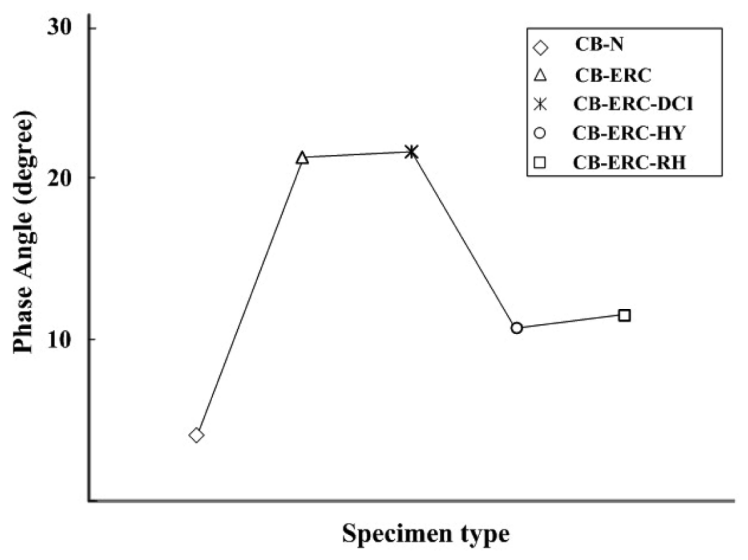

Fig. 6 Plot of phase angle vs. specimen type.

have large values of maximum absolute phase angle compared to that of the specimen with conventional bar. The decrease of maximum absolute phase angle is attributed to the decrease of corrosion resistance of the reinforcement steel in concrete.

The values of relative slope changes in the logarithmic modulus, $\log |Z|$, versus frequency $f$ in cycles per second from Bode plots indicate the similar feature. In Fig. 7, the relative slope changes versus specimen types are plotted. Specimens with epoxy coated bars have large values of slope change compared to the specimen with conventional bar.

The corrosion rate can be estimated through the polarization resistance, $R_{p}$, determined in the simulation of the experimental spectra. This approach is useful especially at very low frequencies when data is difficult to obtain experimentally due to time or equipment limitations. ${ }^{15,16}$ Corrosion current density is calculated using the Stern-Geary equation as expressed below.

$$
I_{C}=\frac{B}{R_{p}}
$$

Where, " $B$ " is a function of the anodic and cathodic Tafel slopes, and

$$
B=\frac{\beta_{a} \beta_{c}}{2.303\left(\beta_{a}+\beta_{c}\right)}
$$

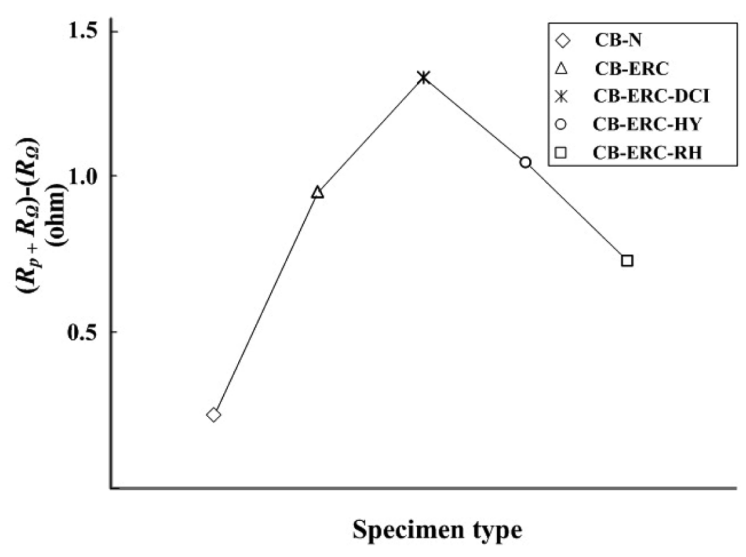

Fig. 7 Plot of $\left(R_{p+} R_{\Omega}\right)-\left(R_{\Omega}\right)$ vs. specimen type.
For the reinforcing bar corrosion, a " $B$ " value of $26 \mathrm{mV}$ has been used in the calculation for the steel in the active and passive stage, respectively as in other studies.

The guidelines for estimating the rate of corrosion from measured current density in reinforced concrete is given in Table 4. This correlates with the transition from moderate to high corrosion conditions. Rodriguez et al. ${ }^{17}$ found that cracking due to corrosion occurs when the section loss is in the region $10 \sim 30 \mu \mathrm{m} /$ year for cover/rebar diameter ratios of 1 to 3 . In the case of localized pitting, corrosion rates can be $5 \sim 10$ times the general corrosion rate.

Table 5 illustrates $R_{p}$ obtained from the impedance spectra simulation, the corrosion current densities calculated using SternGeary equation and the corrosion current densities obtained from the linear polarization tests. Test results in this study show that the current density of the specimen with conventional steel is $0.893 \mu \mathrm{A} / \mathrm{cm}^{2}$ which means the steel bars are in moderate or high corrosion condition based on the criteria for corrosion rate of steel in concrete. However, the specimens with epoxy coated bars show that the current densities are below $0.1 \mu \mathrm{A} / \mathrm{cm}^{2}$ and they are in a passive condition as illustrated in Fig. 8 (a) and (b). These results were equivalent to those corrosion rates determined by the linear polarization measurement for estimating the rate of corrosion based on the guidelines.

The value $R_{p}$ from Nyquist plot is the most relevant parameter since it represents the corrosion resistance compared to other impedance spectra. It is evident from the results that the corrosion parameters of the reinforcing steel are in the usual expected pattern in accordance with the likelihood of active corrosion in the five different slab specimens. Impedance measurement in the low frequency region provides information related to surface corrosion occurring in reinforced concrete. The polarization resistance obtained impedance simulation, especially the value $R_{p}$ from Nyquist plot, can be used to characterize the degree of corrosion for steel in chloride contaminated concrete structures.

\subsection{Effectiveness of epoxy coating with local damage}

The Florida DOT performed a series of laboratory and fields studies to find possible reasons for corrosion of epoxy-coated rein-

Table 4 Criteria for corrosion rate of steel in concrete.

\begin{tabular}{c|c}
\hline Corrosion rate $\left(\mu \mathrm{A} / \mathrm{cm}^{2}\right)$ & Corrosion condition \\
\hline \hline$I_{\text {corr }}<0.1$ & Passive condition \\
\hline $0.1<I_{\text {corr }}<0.5$ & Low to moderate corrosion \\
\hline $0.5<I_{\text {corr }}<1.0$ & Moderate to high corrosion \\
\hline $1.0<I_{\text {corr }}$ & High corrosion \\
\hline
\end{tabular}

Table 5 Corrosion current densities of specimens from EIS

\begin{tabular}{|c|c|c|c|c|}
\hline \multirow[b]{2}{*}{ Specimens } & \multicolumn{2}{|l|}{ EIS } & \multicolumn{2}{|c|}{ Polarization } \\
\hline & $\begin{array}{c}R_{p} \\
\left(\mathrm{ohm} \mathrm{cm} \times 10^{6}\right)\end{array}$ & $\begin{array}{c}I_{\text {corr }} \\
\left(\mu \mathrm{A} / \mathrm{cm}^{2}\right)\end{array}$ & $\begin{array}{c}R_{p_{2}} \\
\left.\text { (ohm cm } \times 10^{6}\right)\end{array}$ & $\begin{array}{c}I_{\text {corr }} \\
\left(\mu \mathrm{A} / \mathrm{cm}^{2}\right)\end{array}$ \\
\hline CB-N & 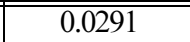 & 0.893 & "0.036 & 0.715 \\
\hline CB-ERC & 0.520 & 0.050 & 1.567 & 0.0168 \\
\hline CB-ERC-DCI & 0.754 & 0.0345 & 2.723 & 0.00957 \\
\hline CB-ERC-HY & 0.456 & 0.0570 & 1.078 & 0.0244 \\
\hline CB-ERC-RH & 0.538 & 0.0483 & 1.698 & 0.0154 \\
\hline
\end{tabular}
and Polarization test results. 


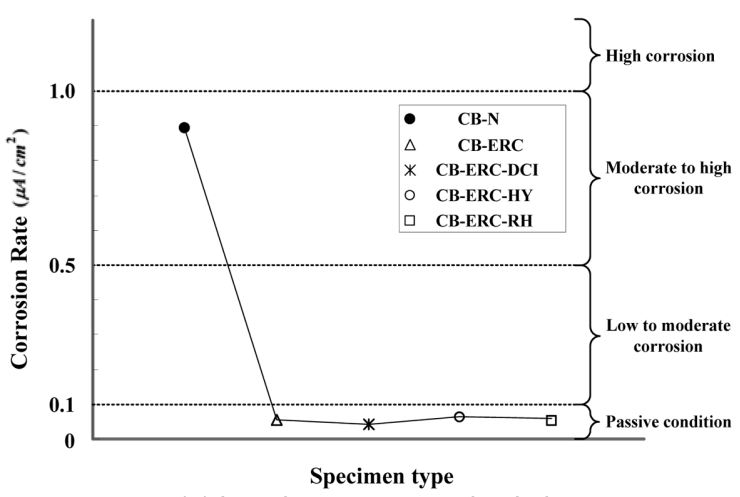

(a) Inpedance spectra simulation

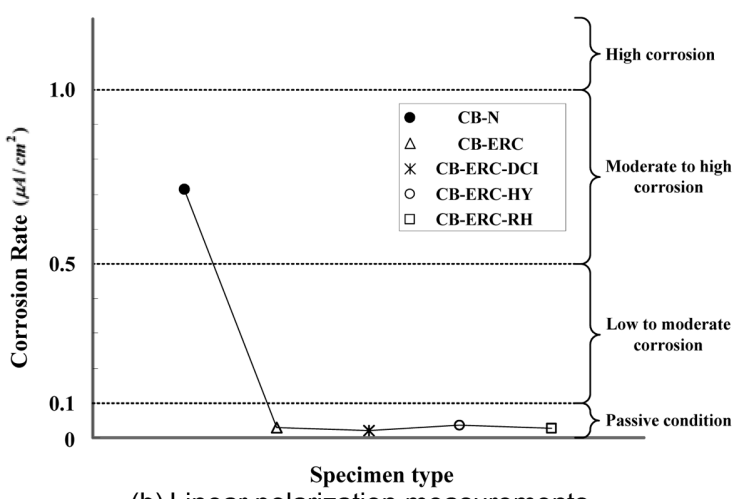

(b) Linear polarization measurements

Fig. 8 Plot of corrosion rate vs. specimen type to determin corrosion condition.

forcement. The research suggested that electrochemical disbanding of epoxy coatings could be initiated due to exposure to salt water and subsequent macrocell action. It was assumed that handling and storage in a salty environment caused additional surface damage of the coating.

In this study of epoxy-coated bars, the epoxy coating was intentionally damaged by drilling four holes of $3.2 \mathrm{~mm}$ diameter through the coating. This study of electrochemical impedance spectroscopy tests indicates that the resistance against the charge transfer through the coating is an order of magnitude higher than that of the reference steel bars. These results were similar to those corrosion rates determined by the linear polarization measurement as indicated. Epoxy coating avoids corrosion reaction although the coating is damaged. The epoxy coating extends the service life and in the case of local damage, the epoxy coating is still effective. Considering this test results, an extension of service life seems to be possible, compared to uncoated reinforcement by means of a durable of limitation of the cathodic area.

\subsection{Effectiveness of corrosion inhibitors}

To compare the effectiveness of corrosion inhibitors, the specimens with epoxy-coated bars and no corrosion inhibitors were used as the control specimen. Sodium nitrite is a typical anodic corrosion inhibitor. It is known that nitrite ions compete with chloride ions for ferrous ions and react with ferrous ions to produce ferric oxide. ${ }^{17,18}$

This reaction is much more rapid than the transport of ferrous ions via chloride ion complex formation and nitrite ions aid in the production of the stable passive layer.

$$
2 \mathrm{Fe}^{2+}+2 \mathrm{OH}^{-}+2 \mathrm{NO}_{2} \rightarrow 2 \mathrm{NO} \uparrow+\mathrm{Fe}_{2} \mathrm{O}_{3}+\mathrm{H}_{2} \mathrm{O}
$$

The corrosion current densities of specimens containing a combination of amines and esters or mixtures of organic alkenyl dicarboxyl acid salts and additives are almost equivalent with the specimen with epoxy-coated bars and no inhibitors. However, the corrosion protection performance provided by calcium nitrite is better than other three specimens. These results were similar to those corrosion current densities determined by linear polarization measurement as indicated in Fig. 8. Considering the electrochemical techniques used to study the inhibiting action of nitrites for reinforcing steel in chloride environment, compared to other inhibitors, it has been proved that they detail the corrosion process, although only from polarization resistance it is possible to obtain a quantitative value of the corrosion rate.

\section{Conclusions}

Based on this research from the test results of specimens with 48 weekly cycles of ponding with sodium chloride solution and drying, the following conclusions can be drawn.

1) Impedance measurement in the low frequency region provides information related to surface corrosion occurring in reinforced concrete. The polarization resistance obtained impedance simulation, especially the value $R_{p}$ from Nyquist plot, can be used to characterize the degree of reinforcement corrosion.

2) The corrosion current density can be estimated by knowing the polarization resistance using the Stern Geary equation. The values of corrosion current densities determined by impedance measurement were equivalent to those determined using linear polarization techniques referring the criteria for estimating the rate of corrosion of reinforcing steel in concrete structures.

3) The impedance spectra of the specimens with epoxy-coated bars are mainly governed by the arc of the interfacial film. The resistance against the charge transfer through the coating is an order of magnitude higher than that of the reference steel bars. The epoxy coating extends the service life and in the case of local damage, the epoxy coating is still effective.

4) The corrosion protection performance provided by calcium nitrite appears to be better than those by a combination of amines and esters or mixtures of organic alkenyl dicarboxyl acid salts and additives.

\section{Acknowledgements}

This work is supported by Soongsil University Research Fund. The financial support is gratefully acknowledged.

\section{References}

1. Uhlig, Herbert H. and Revie, Winston R., "Corrosion and Corrosion Control," An Introduction to Corrosion Science and Engineering, John Wiley \& Sons, Inc, New York, 1985, 441 pp.

2. Jones, D. A., Principles and Prevention of Corrosion, Macmillan Publishing Company, New York, NY, 1996, 572 pp.

3. Baidis, J. M. and Rosenberg, A. M., "The Inhibitors of Chloride-Induced Corrosion in Reinforced Concrete by Calcium Nitrite," Cement, Concrete, Aggregates, Vol. 9 No. 1, 1987, pp. 30 33. 
4. ASTM C 109-92, "Standard Test Method for Determining the Effects of Chemical Admixtures on the Corrosion of Embedded Steel Reinforcement in Concrete Exposed to Chloride Environments," 1999 Annual Book of ASTM Standards, Vol. 04.02, American Society for Testing and Materials, West Conshohocken, PA. 1999.

5. Bonanos, N., Steele, B. C. H., Buter, E. P. Johnson, W. B., Worrell, W. L., MacDonald, D. D., and McKubre, M. C. H., Application of Impedance Spectroscopy, Ch. 4, edited J. R. MacDonald, Wiley \& Sons, NY, 1987.

6. John, D. G., Searson, P. C., and Dawson, J. L., "Use of AC Impedance Technique in Studies on Steel in Concrete in Immersed Conditions," British Corrosion Journal, fl6, 1981, pp. $102 \sim 10$.

7. Andrade, C., Soler L., Alonso, C., Novoa, X. R., and Keddam, M., "The Importance of Geometrical Considerations in the Measurement of Steel Corrosion in Concrete by Means of AC Impedance," Corrosion Science, Vol. 37, No. 12, 1995, pp. 2013 2023.

8. Gu, P., Elliot, S., Hristova, H., Beaudoin, J. J., Brousseau, R., and Baldock, B., "A Study of Corrosion Inhibitor Performance in Chloride Contaminated Concrete by Electrochemical Impedance Spectroscopy," ACI Materials Journal, Vol. 94, No. 5, Sep-Oct., 1997, pp. 385 395.

9. Lorentz, T. E., French, C. W., and Leon, R. T., "Corrosion of Coated and Uncoatd Reinforcing Steel in Concrete," Structural Engineering Report No. 92-03, University of Minnesota Center of Transportation Studies, 1992, 204 pp.

10. McDonald, D. B., Pfeifer, D. W., and Sherman, M. R., Corrosion Evaluation of a Epoxy-Coated, Metallic-Clad and Solid Metallic Reinforcing Bars in Concrete, Publication No. FHWA-RD-98-153, Federal Highway Administration, McLean, VA, 1998, $127 \mathrm{pp}$.

11. ASTM C 876-91, "Standard Test Method for Half-Cell Potentials of Uncoated Reinforcing Steel in Concrete," 2002 Annual Book of ASTM Standards, Vol. 03.02, American Society for Testing and Materials, West Conshohocken, 2002, PA.

12. Berke, N. S., Shen, D. F, and Sundberg, K. M., "Comparison of the Polarization Resistance Technique to the Macrocell Corrosion Technique," ASTM Special Technical Publication, Symposium on Corrosion Rates of Steel in Concrete, Baltimore, 1990, pp. 38 51.

13. Hope, B. B., Page, J. A., and Ip, A. K. C., "Corrosion Rate of Steel in Concrete," Cement and Concrete Research, Vol. 16, No. 5, 1986, pp. 771 786.

14. Balma, J., Darwin, D., Browning J, and Locke, C. E, "Evaluation of Corrosion Protection Systems and Corrosion Testing Methods for Reinforcing Steel in Concrete," SM Report 05-1, The University of Kansas Center for Research, Inc., Lawrence KS, 2005, 517 pp.

15. Choi, O. C. and Jung, S. Y., "Corrosion Evaluation of Epoxycoated Bars in Chloride Contaminated Concrete Using Linear Polarization Test," KCI Concrete Journal, Submitted.

16. Pfeifer, D. W. and Scali, M. J., "Concrete Sealers for Protection of Bridge Structures," National Cooperative Highway Research Board Program Report 244, Transportation Research Board, National Research Council, Washington, D. C., 1981, 138 pp.

17. Zhang, J., Monterio, P. J. M., and Morrison H. F., "Noninvasive Surface Measurement of Corrosion Impedance of Reinforcing Bar in Concrete-Part 1: Experimental Results," ACI Materials Journal, V. 98, No. 2, March-April, 2001, pp. 116 125.

18. Gamry, Electrochemical Measurement System Software Installation Manuals, Revision 3.1, Gamry Instruments Inc, 1999.

19. Allyn, M. and Franz G. C., "Corrosion Tests with Concrete Containing Salts of Alkenyl-Substituted Succinic Acid," ACI Materials Journal, Vol. 98, No. 3, May-June, 2001, pp. 224 232.

20. Rodriguez, J, Ortega, L. M. Garcia, A. M. Johansson, L. and Peterson, K., "On Site Corrosion Rate Measurements in Concrete Structures Using a Device Developed under Eureka Project EU-401," Proc. of International Conf. on Concrete Across Borders, Vol. 1, Odense, Denmark, June, 1994, pp. 171 185. 